origem marinha que apresenta atividade LRA, tendo sido previamente sintetizado [1] em 24 etapas, mas faltando estudos biológicos e dos seus análogos.

Kenichi Murai, Mitsuhiro Arisawa (Universidade de Osaka, Japão) e colegas desenvolveram uma síntese total de anselona $\mathrm{A}$ em 17 etapas e realizaram uma triagem biológica deste composto, bem como de análogos com outros grupos substituintes na posição do grupo acetoxilo (OAc). A equipa de investigação iniciou a síntese com o (+)-esclareolido (sclareolide), uma lactona sesquiterpénica natural, que foi convertida primeiramente num diol, depois num álcool alílico terciário estabilizado por um grupo triflato e, finalmente, oxidação do álcool primário para introduzir um grupo aldeído. 0 intermediário resultante foi submetido a uma reação de ciclização de Prins com cis- $\boldsymbol{\gamma}$-hidroxicarvona para formar $\mathrm{o}$ anel de tetra-hidropirano do composto alvo. Finalmente, o grupo triflato foi removido e introduzido o grupo acetato, originando a anselona $\mathrm{A}$.

Estes investigadores obtiveram a anselona $\mathrm{A}$ numa síntese com 17 passos, a qual inclui a sequência linear mais longa de 13 passos a partir do (+)-esclareolido. Sintetizaram também análogos em que o grupo OAc foi substituído por grupos hidroxilo $(\mathrm{OH})$ ou metoxilo (OMe) com vista a estudos de bioatividade, e verificaram que o análogo com o grupo $\mathrm{OH}$ livre tem maior atividade LRA que o composto original.

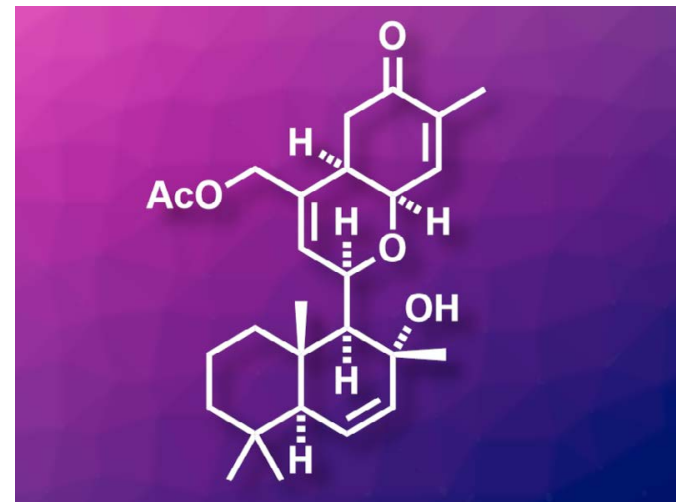

Crédito: ChemistryViews

$>$

\section{Ana Paula Esteves}

aesteves@quimica.uminho.pt

\section{Fontes}

Concise Synthesis of Ansellone A, chemistryviews.org/details/news/11293086/ Concise_Synthesis_of_Ansellone_A.html (acedido em 16/03/2021).

M. Yanagihara, K. Murai, N. Kishimoto, T. Abe, S. Misumi, M. Arisawa, Org. Lett. 2021, 23, 1720-1725. DOI: 10.1021/acs.orglett.1c00151.

[1] W. Zhang, H. Yao, J. Yu, Z. Zhang, R. Tong, Angew. Chem. Int. Ed. 2017, 56, 4787-4791. DOI: 10.1002/anie.201701879.

\title{
Sistema de Administração Oral de Insulina
}

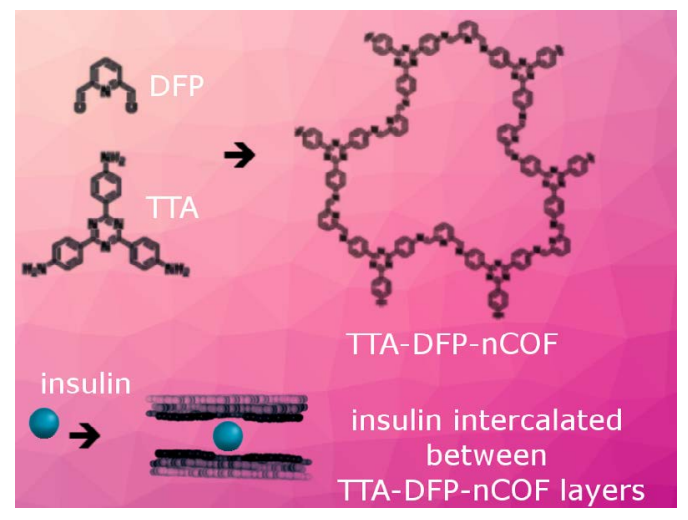

Crédito: ChemistryViews

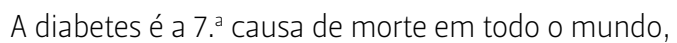
afeta cerca de $10 \%$ da população mundial (tendo quadruplicado a sua prevalência desde a década de 1980) e é responsável por cerca de 15\% dos custos diretos de saúde. Na diabetes tipo 1, a terapia com insulina permite controlar e regular os níveis de g'lucose no sangue mediante injeção ou através de sistemas de perfusão contínua. Até ao momento, estes são os sistemas disponíveis para a administração de insulina, tornando-se útil o desenvolvimento de outros mecanismos, como por exemplo, a administração oral desta hormona essencial.

Ali Trabolsi (New York University Abu Dhabi, Abu Dhabi, Emirados Árabes Unidos) e colegas desenvolveram nanopartículas de estrutura orgânica covalente (nCOF = covalent organic framework nanoparticles) ligada a imina para administração oral de insulina. De acordo com estes investigadores, este sistema de administração oral pode substituir as injeções subcutâneas tradicionais.

Esta equipa de investigação usou como reagentes 2,6-diformilpiridina (DFP) e 4,4',4"'-(1,3,5-triazina-2,4,6-triil)trianilina (TTA) tendo desenvolvido uma 
nCOF gastrorresistente constituída por nanofolhas em camadas mediante um método de crescimento "semeado" (seeded growth-method). A insulina foi colocada entre as camadas das nanofolhas, ficando assim protegida dos fluídos digestivos in vitro, a qual foi libertada por "resposta" à glucose. Esta libertação da insulina induzida por hiperglicemia foi confirmada in vivo em ratos diabéticos sem efeitos tóxicos percetíveis.

Este sistema é biocompatível, altamente estável no estômago, específico, rápido e potencialmente capaz de fornecer a quantidade correta de insulina com base no nível de g'ucose no sangue da pessoa com diabetes. De acordo com a equipa de investigação, o sistema de administração oral de insulina baseado em nCOF pode ser uma alternativa às injeções subcutâneas tradicionais. Para este sistema de administração oral de insulina foi realizado um pedido de patente nos EUA, o qual se encontra pendente.

\section{$>$}

Ana Paula Esteves

aesteves@quimica.uminho.pt

\section{Fontes}

Insulin oral delivery system, chemistryviews.org/details/news/11295461/Insulin_ Oral_Delivery_System.html (acedido em 09/04/2021).

F. Benyettou, N. Kaddour, T. Prakasam, G. Das, S. K. Sharma, S. A. Thomas, F. B.-Sari, J. Whelan, M. A. Alkhalifah, M. Khair, H. Traboulsi, R. Pasricha, R. Jagannathan, N. M.-Soulimane, F. Gándara, A. Trabolsi, Chem. Sci. 2021, 12, 6037-6047. DOI: 10.1039/DOSC05328G.

\section{Resíduos de Pesticidas: Como Afetam a Agricultura Biológica?}

Fungicidas, herbicidas e inseticidas são parte integrante da agricultura moderna convencional como agentes protetores das plantações, contribuindo para o controlo de pragas, de ervas daninhas e de doenças das plantas. Nos últimos vinte anos, o uso de pesticidas aumentou mais de $40 \%$ e, atualmente, são utilizados em todo o mundo, por ano, mais de 4,1 milhões de toneladas. Apesar dos seus benefícios para o rendimento das culturas, o uso intensivo e generalizado de pesticidas coloca muitas preocupações ambientais devido à contaminação dos recursos naturais. Em oposição, a agricultura biológica evita a adição de substâncias sintéticas e depende de um ecossistema de solo saudável. No entanto, algumas plantações de agricultura biológica ocorrem em terras que, no passado, foram tratadas com pesticidas. Não é ainda claro se os pesticidas têm uma presença duradoura nestes terrenos e quais os efeitos de longo prazo que podem ter sobre os micróbios e fungos benéficos do solo.

Thomas D. Bucheli, Florian Walder (Agroscope, Zurique, Suíça), Marcel G. A. van der Heijden (Agroscope e Universidade de Zurique, Suíça) e colegas examinaram os níveis de pesticidas e o seu impacto

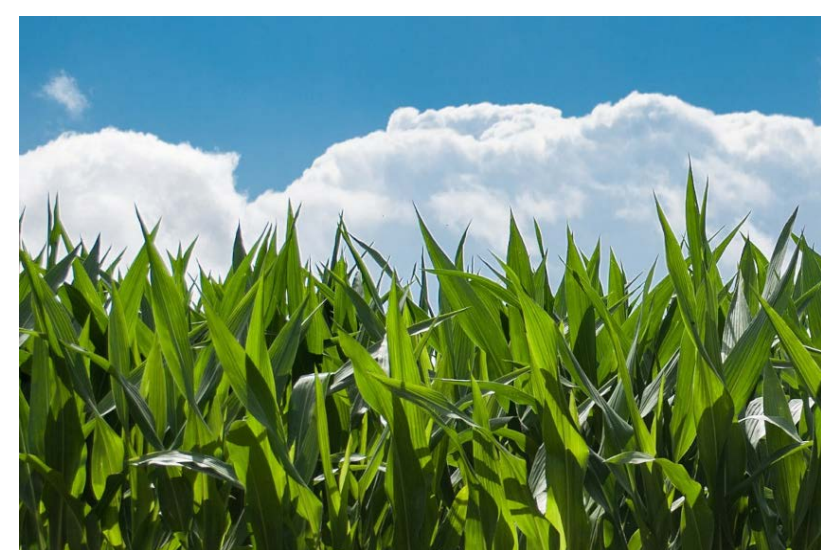

Crédito: ChemistryViews

na saúde do solo em herdades usando agricultura convencional ou biológica, incluindo algumas que foram convertidas para métodos orgânicos. Estes investigadores mediram as concentrações de 46 pesticidas, usados regularmente e dos seus produtos de degradação, em amostras retiradas de 100 campos que faziam parte de explorações agrícolas convencionais ou orgânicas. Os resíduos de pesticidas foram extraídos das amostras de solo e os extratos analisados por cromatografia líquida de alta eficiência acoplada a espectrometria de massa tandem (HPLC-MS/MS).

A equipa de investigadores encontrou resíduos de pesticidas em todos os locais, inclusive em explorações agrícolas que haviam sido convertidas para agricultura biológica há mais de 20 anos. Perante isto, ou os 